\title{
MANERAS CINEMATOGRÁFICAS DE MIRAR
}

\author{
Basilio CASANOVA
}

Universidad Autónoma de Tamaulipas

\section{La mirada en el cine clásico}

En Centauros del desierto (The Searchers, 1956), de John Ford, un magnífico exponente del cine clásico -tardío- de Hollywood, antes incluso de que el relato dé comienzo -es decir: en los títulos de crédito-, un muro se levanta, infranqueable, ante los ojos del espectador. Un muro que se erige así en precisa metáfora del proceso de construcción del relato que sigue.
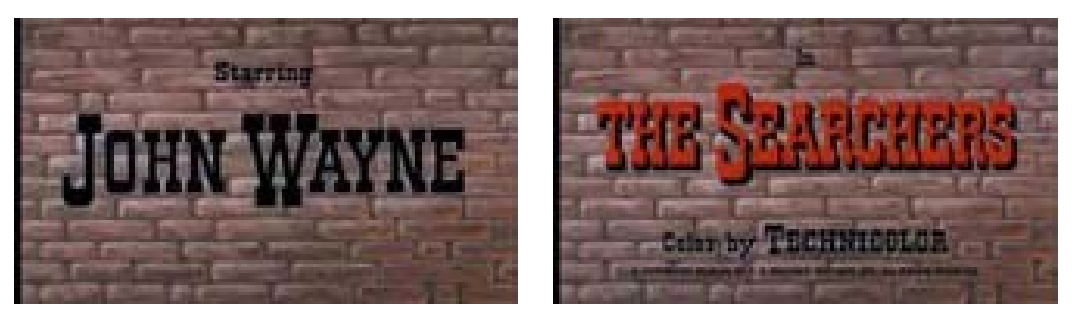

Pero habría que añadir inmediatamente que ese proceso de construcción narrativa lo será, simultáneamente, de un espacio vedado a la mirada -a nuestra mirada: el espacio, entonces, de lo no visible. Porque, ¿no es de lo invisible de lo que es también metáfora ese muro que se levanta tras las letras que forman el nombre -y el apellido- del director del filme?

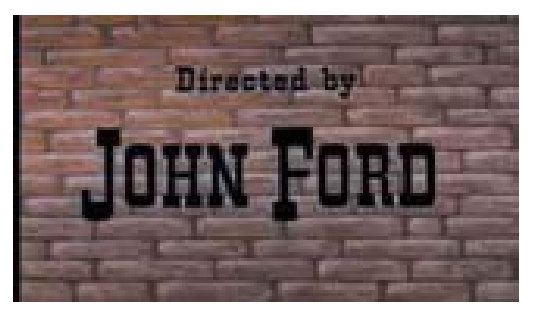

Ese muro localiza un espacio del que ese nombre afirma -y firma- ser el guardián. Y bien, nuestra hipótesis rectora es que lo que tanto ese muro como esa firma garantizan es la posibilidad misma de relato -de que haya relato-. 
Pocas imágenes por eso tan nítidas, como éstas, de la manera de trabajar del cine clásico, de lo que en todo film clásico está realmente en juego: la construcción de una trama, de un trayecto para el deseo. Porque para que haya deseo, para que el deseo exista -se constituya como tal- es necesario, como supo enseñarnos Sigmund Freud, que exista antes una prohibición -no hay deseo sin prohibición previa-.

Pues bien, veamos entonces cómo se inscribe esa prohibición en Ethan, el protagonista masculino de Centauros del desierto, interpretado en el film por John Wayne.
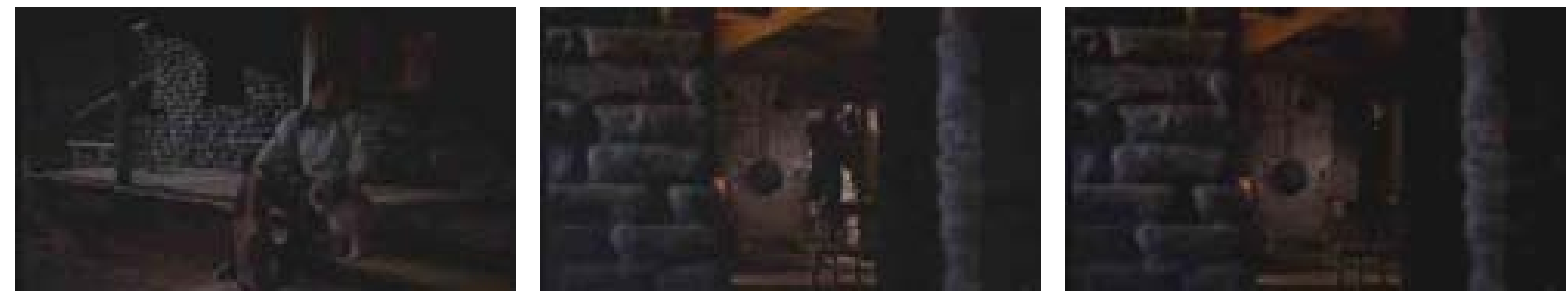

Es de noche y la familia Edwards acaba de retirarse a sus habitaciones. Fuera, en el porche de la casa, se encuentra Ethan; a su lado, tan solitario como él, un perro. El hombre mira entonces hacia el interior de la casa y ve a través de las puertas -exterior e interior-abiertas, a su hermano Aaron, doblemente reencuadrado, cerrando la puerta del dormitorio en el que sabemos se encuentra ya su esposa Marta, esa mujer de la que Ethan -el hombre cuyo punto de vista compartimos, excepcionalmente, en estos momentos- sigue todavía enamorado.
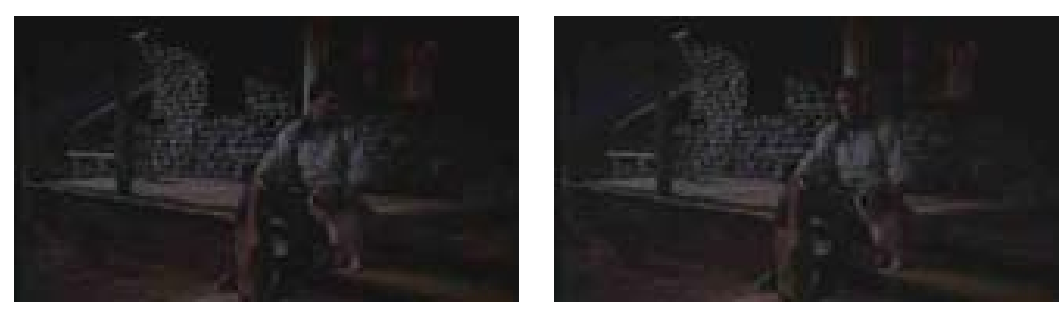

Cuando regresamos al protagonista, a éste lo encontramos acariciando, pensativo, al perro. Y es que el destino del héroe, protagonista del filme clásico, es muy a menudo la soledad.

Pues bien, ahí, en ese No trespassing, en esa prohibición claramente escrita, reside una de las claves de la función de esa figura esencial del cine clásico que es la del héroe. Porque pocas cosas tan heroicas - tan dolorosas, tan hondamente humanas- como 
esa: sustentar el lugar - a este lado de una puerta cerrada que acota el espacio prohibido, sagrado- de lo no visible.

De lo cual se deduce que lo esencial en el filme clásico es la trama, no la aventura visual del espectador.

\section{La mirada en el cine manierista}

Eso por lo que respecta a la mirada cinematográfica clásica. Existen, sin embargo, otras maneras, cinematográficas, de mirar. Esa otra manera de mirar, propia del cine que Jesús González Requena llama manierista ${ }^{1}$, que inaugura, por ejemplo, Ciudadano Kane (Citizen Kane, 1941), de Orson Welles:
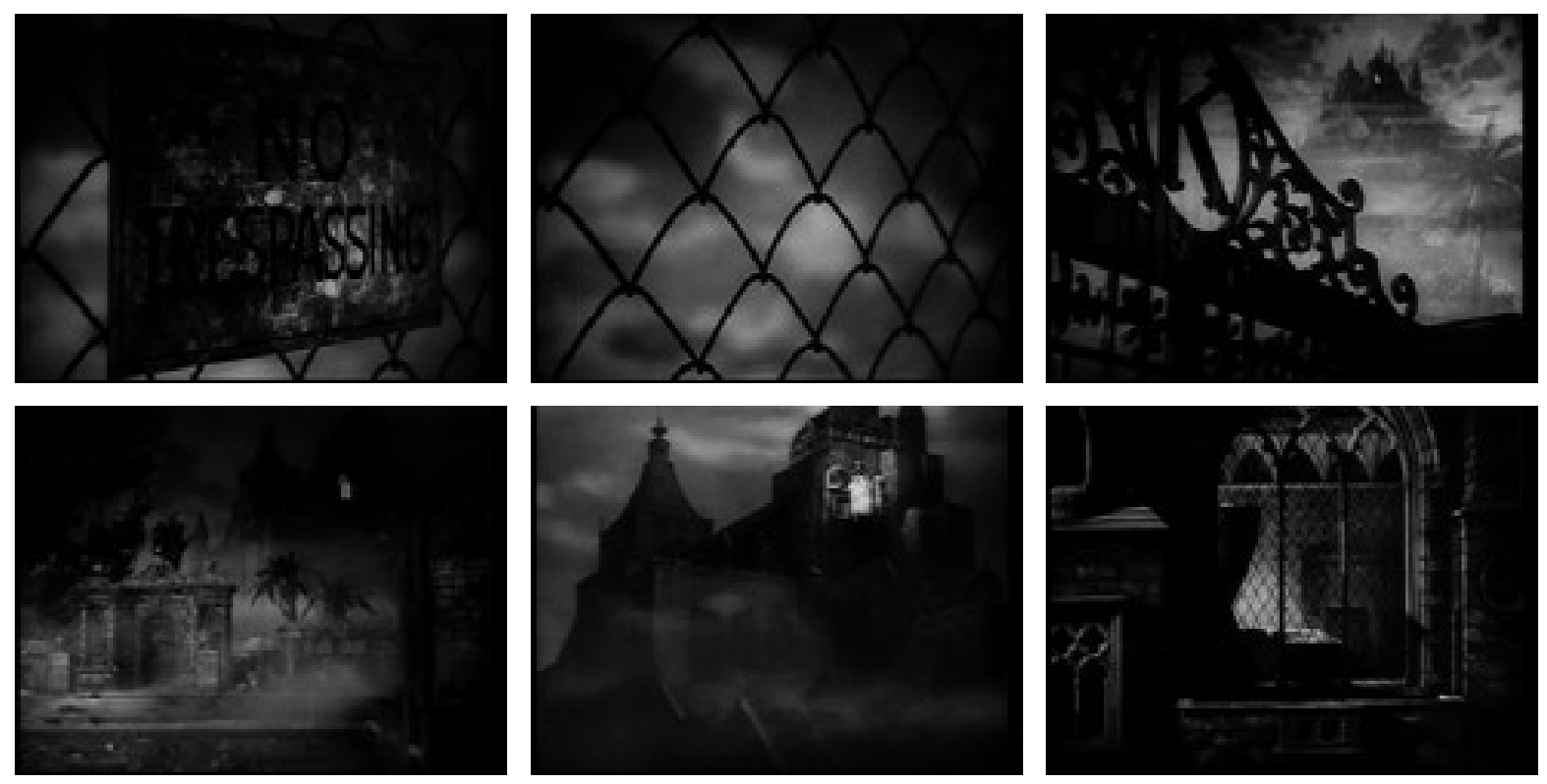

Donde se inauguraba una nueva manera de mirar en lo esencial diferente a la que rigiera en el cine clásico de Hollywood, que reinaba entonces en todo su apogeo. Pues si con el cine clásico la cámara sometía su mirada al orden interior del relato, plegándose al ámbito de las miradas de los personajes que lo habitaban, con Ciudadano Kane, en cambio, la cámara encontró una nueva autonomía: la suficiente para introducir una nueva mirada, externa a los personajes que poblaban el universo narrativo, y a la que el espectador era convocado por la enunciación misma del film. El intenso movimiento de

\footnotetext{
${ }^{1}$ Véase al respecto el libro a nuestro entender ya fundamental: GONZÁLEZ REQUENA, Jesús, 2006: Clásico, manierista, postclásico. Los modos del relato en el cine de Hollywood, Castilla ediciones, Valladolid, 2006.
} 
penetración de aquella mirada formulaba explícitamente su desafío violando la prohibición del cartel de No trespassing que vedaba la puerta cerrada, acotando el territorio de Xanadú ${ }^{2}$.

Pero es el caso también de Rebeca (Rebecca, 1940), de Alfred Hitchcock, en la que un también "intenso movimiento de penetración" de la mirada traspasaba la puerta, cerrada, de Manderley. Si bien aquí lo hacía guiada por la voz en off de quien otrora habitara esa mansión -en lo que se podría considerar, entonces, como una suerte de mirada retrospectiva-.
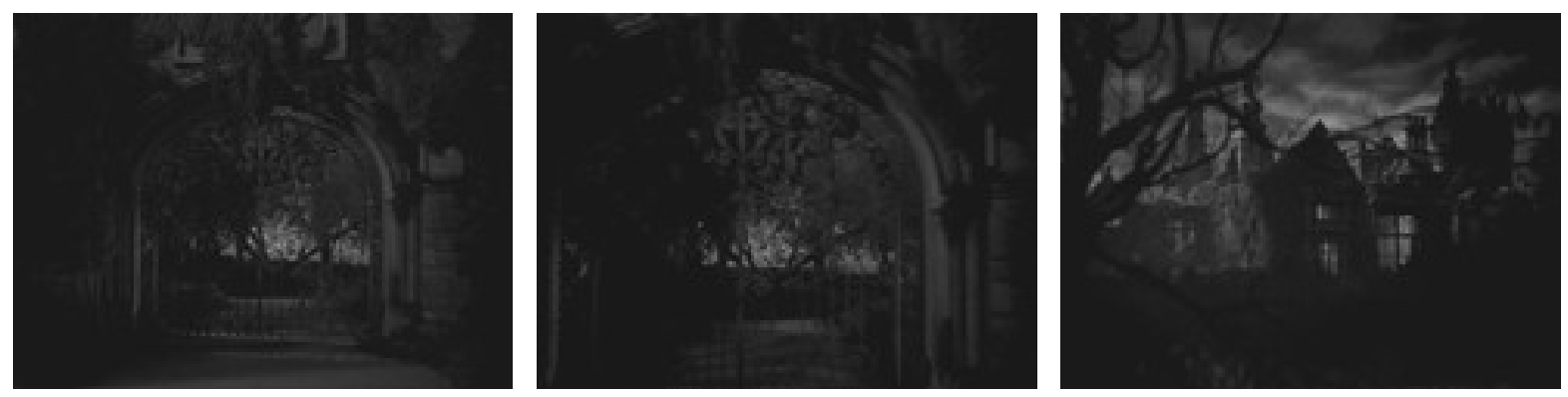

El cine manierista -hecho a la manera del cine clásico- es un cine que, lejos de respetar la prohibición de No trespassing, la viola. No hay pues en este cine pared metafórica alguna que se levante, tal y como sucedía en Centauros del desierto, ante nuestros ojos de espectadores marcando un límite para la mirada.

El cine manierista formula, por el contrario, una muy explícita invitación a mirar, a penetrar más allá.

Así, en La ventana indiscreta (Rear Window, 1954), también de Hitchcock, si bien el título del filme aparece todavía superpuesto a un ventanal con las persianas bajadas -hecho que impide que podamos ver lo que hay más allá-, cuando el nombre del director aparece en imagen, una mano que no vemos se ha encargado ya de enrollarlas, invitándonos así a acceder a un patio interior en el que la cámara -y con ella la mirada del protagonista del film y la del espectador- habrá de penetrar.

\footnotetext{
${ }^{2}$ GONZÁLEZ REQUENA, Jesús y ORTIZ DE ZÁRATE, Amaya, 2000): Léolo. La escritura fílmica en el umbral de la psicosis, Ed. de la Mirada, Valencia, 2000, p. 36.
} 

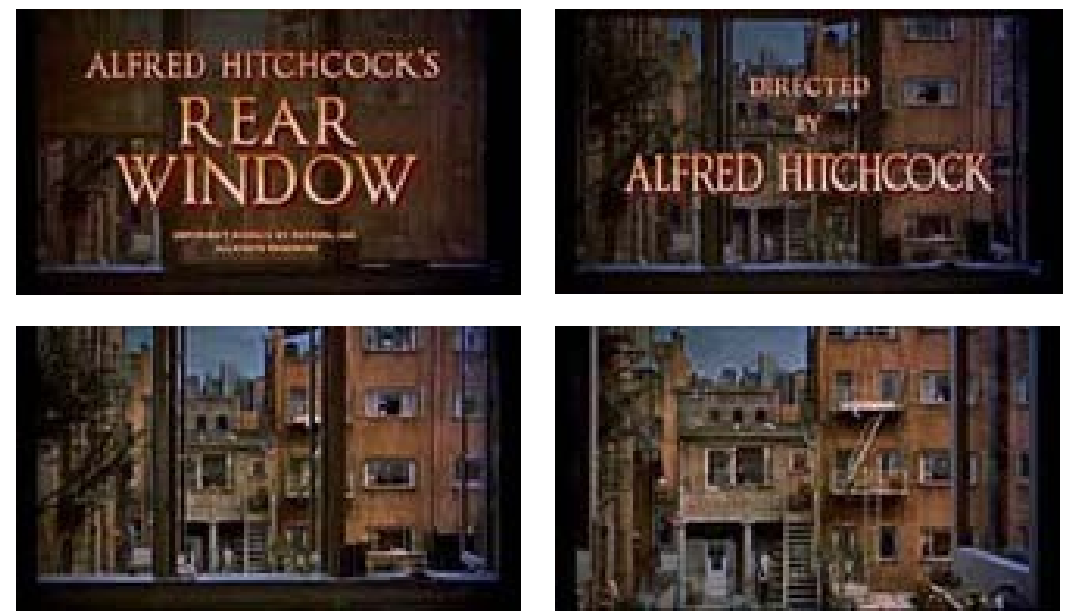

Y convendría añadir que esa pasión por mirar tiene que ver, en La ventana indiscreta, con la posición del protagonista masculino del filme, como sabemos, postrado, pasivizado, condenado, también él, a la posición de mirón.

Y mirar es también lo que hará Norman Bates en Psicosis (Psycho, 1960), film esencial en la historia del cine.
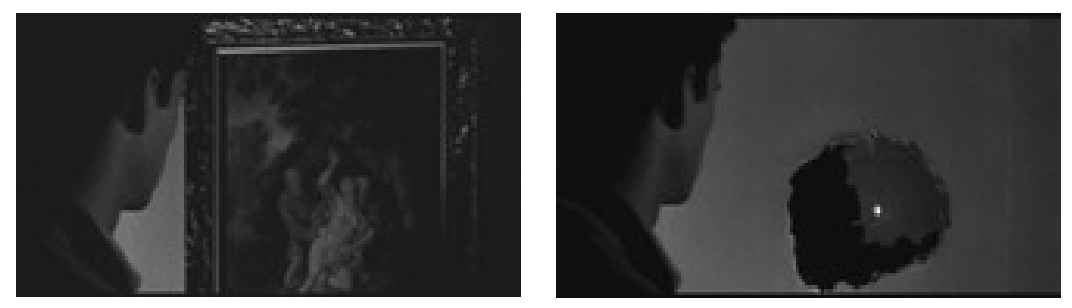

Demolido ya todo muro simbólico, toda representación -ese cuadro de Susana y los viejos que Norman contempla momentos antes de descolgarlo de la pared-, el ojo agigantado por la escala del gran primer plano- se abisma en una visión a la que ya ninguna prohibición, ningún muro -ninguna pared- pone freno.
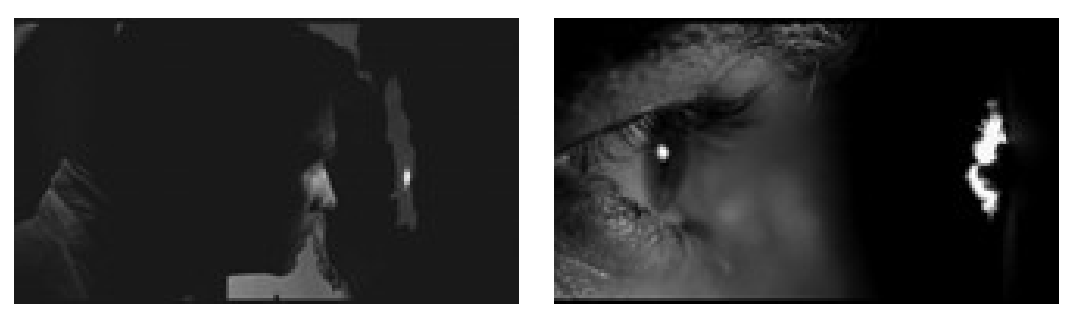


\section{La mirada en el cine de vanguardia}

Pero lo que el cine manierista hace es realizar, dentro de una estructura narrativa clásica, el presupuesto básico que regía -y latía- ya en el cine de vanguardia de principios del siglo XX: el de la violencia en -y de- la mirada cinematográfica.

Así, ejemplares filmes vanguardistas como El acorazado Potemkin (Bronenosets Potemkin, 1925), de S. M. Eisenstein o Un perro andaluz (Un chien andalou, 1929), de Luis Buñuel, tematizan una y otra vez, poniéndola en escena, esa violencia.
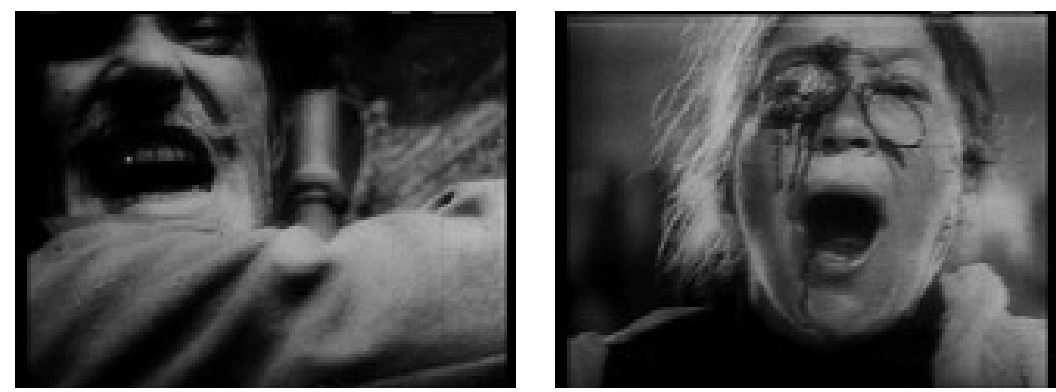

En el caso de El acorazado Potemkin, agrediendo directamente al ojo hasta hacerlo estallar.
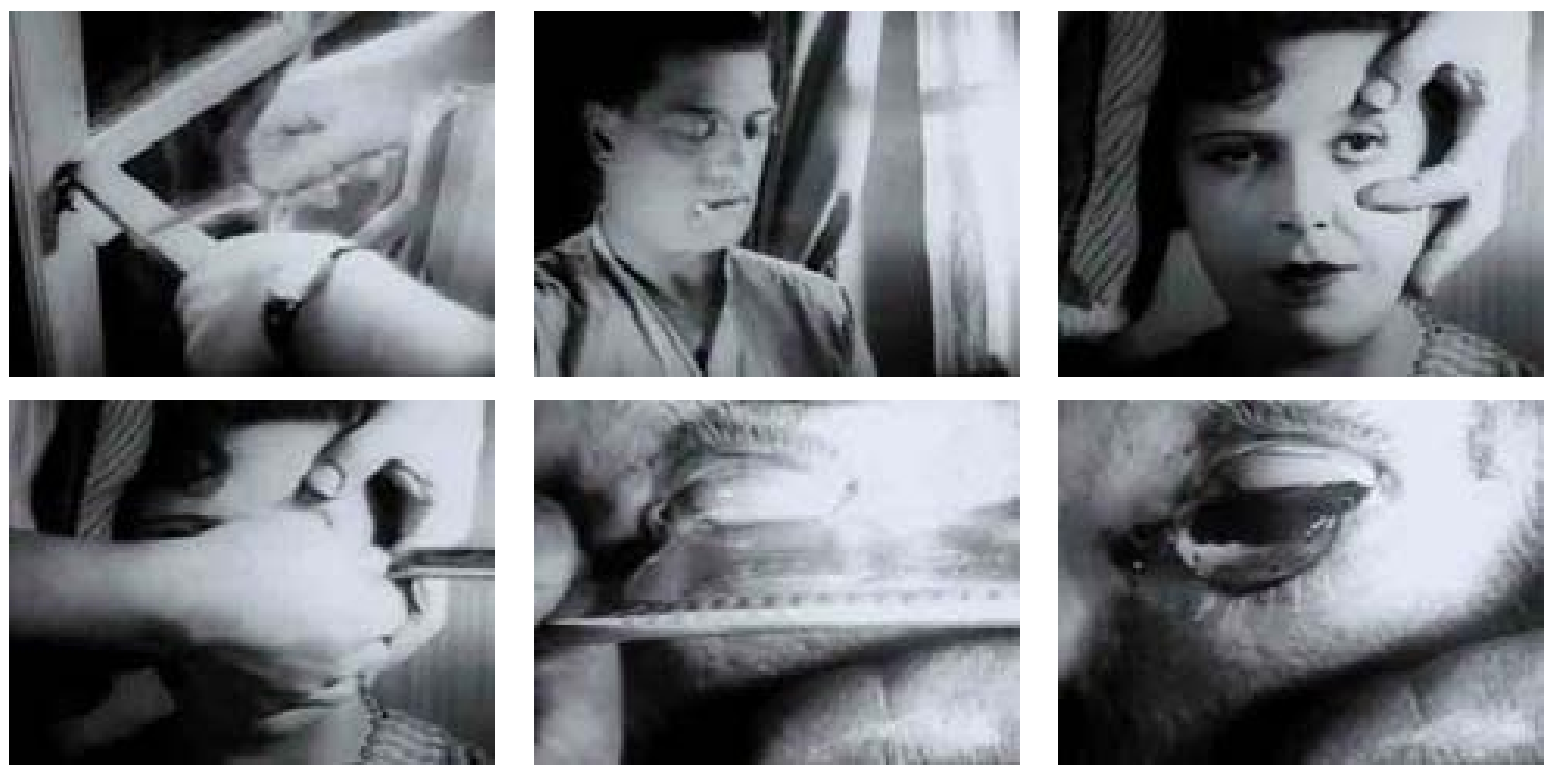

En el caso del film de Luis Buñuel, seccionándolo con una navaja barbera. 

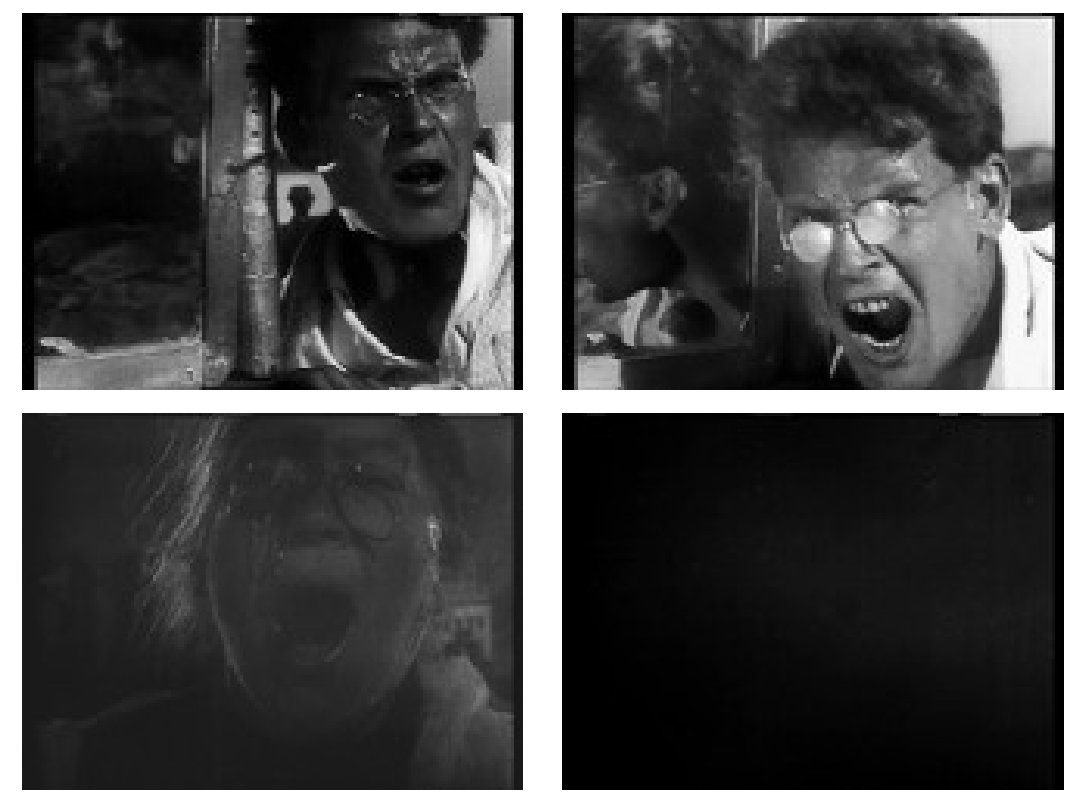

Y si en Un perro andaluz es el propio Luis Buñuel el agente activo de la agresión, en El acorazado Potemkin, un hombre con bastante parecido físico a Eisenstein es quien contempla -desde una posición pasiva- la brutal agresión que concluye con la pantalla en negro, es decir, con el cese de toda visión.

\section{La mirada en el cine postclásico}

¿Y qué sucede con el cine postclásico? ¿Cuál es su manera, cinematográfica, de mirar?

El arranque de Matrix (The Matrix, 2000) podría servirnos muy bien de ejemplo. Una red de números en continua rotación cubre la pantalla.
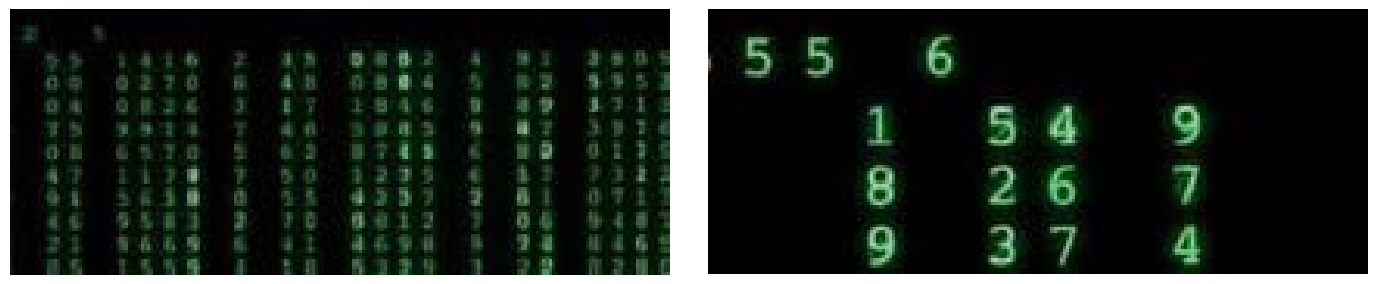
La cámara inicia un movimiento de aproximación hasta mostrarnos el hueco abierto entre los números cinco y seis.
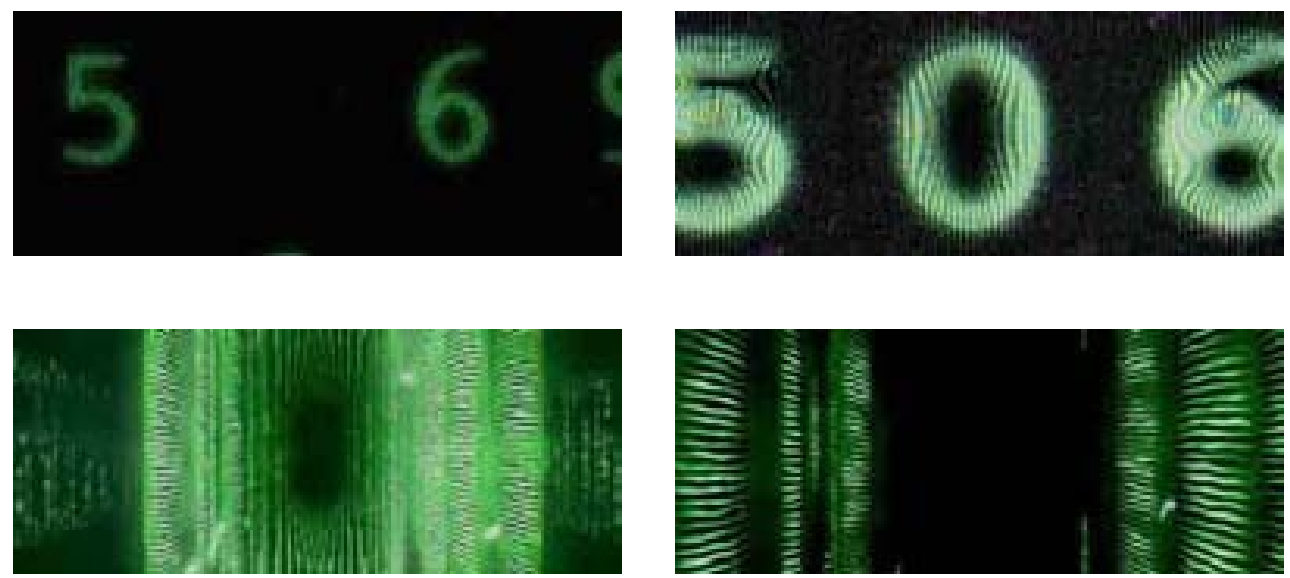

En ese espacio negro se dibuja un cero en cuyo interior se abre una especie de agujero negro, aunque también podría tratarse de un largo y oscuro túnel. Una suerte de intrusión -enter-, entonces, en el útero materno (en la matriz, en el origen mismo).

Y al final de ese túnel aguarda una luz, la luz, pronto tendremos ocasión de descubrirlo, de una linterna. Junto a ésta unos ojos que miran -nos miran- y una pistola.
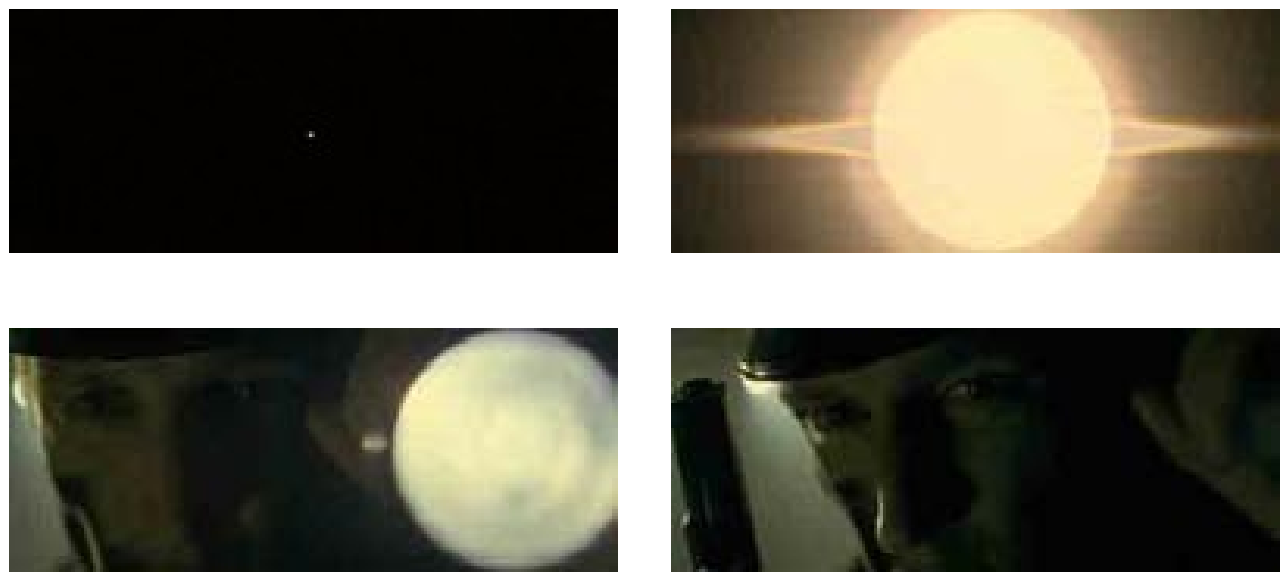

La mirada y, junto a ésta, la amenaza de la violencia que la habita. Una mirada abismada en un espacio originario, oscuro e interior.

Tal es la lógica, violenta, pulsional, que rige la economía visual del cine postclásico. 


\section{Coda}

De manera que una misma tendencia a llevar la mirada al límite mismo de lo visible caracteriza al cine de vanguardia, al manierista y al postclásico. La excepción la constituiría, entonces, el cine clásico de Hollywood que conoció su apogeo durante los años 20, 30 y 40 del pasado siglo y en el que lo esencial sucede fuera del alcance de la mirada del espectador -fuera de campo, en off. Un cine en el que lo fundamental es la trama -narrativa- y no el espectáculo -visual-. 